\title{
Modified endoscopic full-thickness resection of gastric stromal tumor originating from the muscularis propria layer
}

\author{
Xu Tian", Bing Shi", Wei-Qing Chen \\ Department of Gastroenterology, Chongqing University Cancer Hospital, Chongqing 400030, China \\ \#These authors contributed equally to this work. \\ Correspondence to: Wei-Qing Chen, MD. Department of Gastroenterology, Chongqing University Cancer Hospital, No. 181 Hanyu Road, Shapingba \\ District, Chongqing 400030, China. Email: CQCH_ChenWQ@163.com.
}

\begin{abstract}
Endoscopic full-thickness resection (EFTR) is emerging as an approach to resect gastric gastrointestinal stromal tumors originating from the muscularis propria layer (MP-GISTs) because several established endoscopic closure methods and tools have been developed. However, EFTR is performed difficultly due to three challenges: limited luminal insufflation and visualization, insufficient operating space, and inadequate exposure of cutting line. Therefore, we performed a novel method of clip- and snareassisted EFTR (also named as m-EFTR or chen-EFTR) to resect a MP-GIST. This m-EFTR (chen-EFTR) provides a novel approach to resect MP-GISTs through providing distinct endoscopic visualization, adequate exposure of cutting line and sufficient operating space.
\end{abstract}

Keywords: Gastric gastrointestinal stromal tumor (gastric GIST); endoscopic surgery; endoscopic full-thickness resection (EFTR); modified EFTR

Submitted Dec 19, 2019. Accepted for publication Mar 06, 2020.

doi: 10.21037 /jgo.2020.03.12

View this article at: http://dx.doi.org/10.21037/jgo.2020.03.12

\section{Introduction}

Gastric gastrointestinal stromal tumors (GISTs) are potentially malignant and are indicated for resection (1). With the development of several novel endoscopic closure methods and tools, endoscopic full-thickness resection (EFTR) is emerging as an option to resect GISTs originating from the muscularis propria layer (MPGISTs) (2). However, EFTR is performed difficultly due to three challenges (3): (I) leakage of $\mathrm{CO}_{2}$ limits luminal insufflation and endoscopic visualization, (II) insufficient operating space limits the ability to avoid and control serosal bleeding, and (III) inadequate exposure of cutting line increases the risk of abdominal organ injuries. Therefore, we developed a novel method of clip- and snareassisted EFTR (also named as m-EFTR or chen-EFTR) to resect gastric MP-GISTs (Video 1).

\section{Operative techniques}

A 63-year-old woman underwent gastroscope and was determined to have a submucosal tumor (SMT) at the dorsal area of the junction of gastric fundus and body (Figure 1A). Endoscopic ultrasound revealed that the tumor originated from the muscularis propria layer and without lymph node metastasis (Figure 1B). Given the relatively advanced age of the patient, the potential adverse events of a surgical procedure, and the small size of tumor without lymph node metastasis, endoscopic submucosal dissection (ESD) with $\mathrm{CO}_{2}$ insufflation was decided after discussed fully with patient and family members (1).

Expansion of submucosal layer was achieved initially 

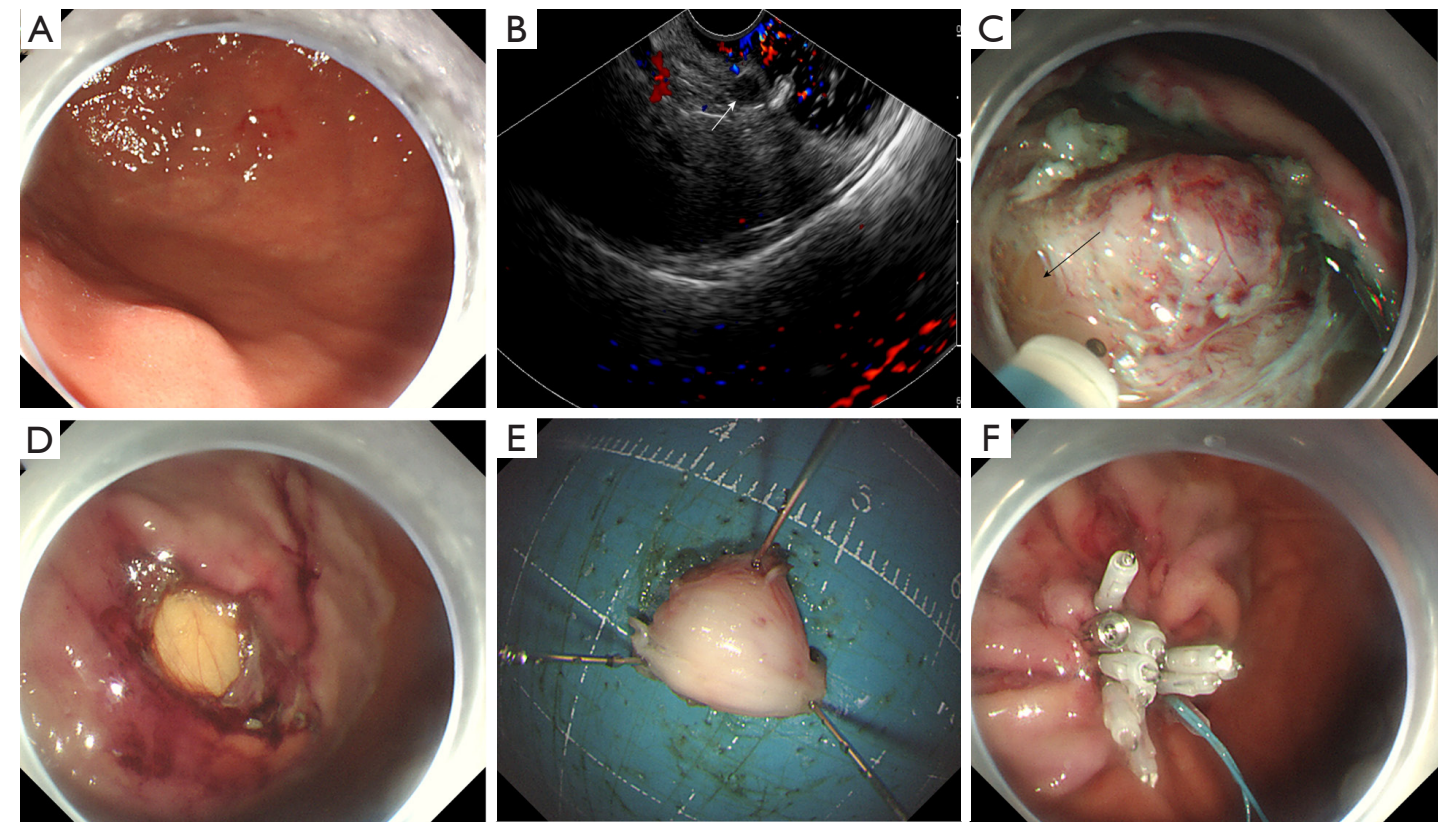

Figure 1 Endoscopic examination and resection of gastric stromal tumor originating from the forth layer. (A) Upper endoscopy showed a submucosal tumor at junction of gastric fundus and body; (B) the tumor originating from the muscularis propria layer, as shown by endoscopic ultrasound (EUS); (C) an occurred micro-perforation during dissection; (D) the defect after removing tumor completely; (E) the submucosal tumor was removed en bloc with a diameter of $1.0 \mathrm{~cm}$; (F) the defect was closed completely with several clips and endoloop.

by injecting a mixture of epinephrine and methylene blue mixed with hydroxyethyl starch solution (Injector Force Max; Olympus; Japan). The location of the tumor was marked using the retracted tip of the Dual-Knife (Olympus; Pennsylvania, USA). And then, the initial mucosal incision and sequent dissections were done with Dual-Knife (Olympus; Kuroishi-shi, Japan). As dissection continued, however, a micro-perforation was caused (Figure 1C). So, we changed to perform EFTR method, but the endoscopic visualization, exposure of cutting line, and operating space were extremely limited. Consequently, we developed a clipand snare-assisted EFTR (also named as m-EFTR or chenEFTR) (Video 1).

We firstly placed a clip (Resolution ${ }^{\mathrm{TM}}$ clip; Boston Scientific; USA) to marginal mucosa of tumor. Secondly, we withdraw the gastroscope from stomach, and then tied a snare (Snare Master; Olympus; Japan) to the distal of the gastroscope. The snare was well positioned to be near the transparent-cap. After that, the gastroscope with the tied snare was reinserted smoothly into stomach. Finally, we freed the snare and then anchored it to the clip. We adequately exposed the cutting line and obtained sufficient operating space through repositioned the snare.
Dissections were easily and safely performed (Figure 1D), and the tumor was completely detached from the gastric wall (Figure 1E). After extracted the tumor with the snare, the defect was closed completely with several clips and an endoloop (Figure 1F). We designed Figure 2 to delineate the key-steps of chen-EFTR technique. The key process of placing clip, anchoring snare, and dissecting tumor were displayed in Figure 2A,B,C,D. The key-steps of closure for defect were delineated in Figure 2E, F, G,H. Repeated abdomen radiography revealed no change of free intraperitoneal air. It is also noted that no postoperative pain or signs of local peritonitis was detected after patient returned to ward. Pathological examination of a $\mathrm{H} \& \mathrm{E}$ slide found that the tumor was composed of spindle cell (Figure $3 A$ ). Immunohistochemically, it was positive for hematopoietic progenitor cell antigen (CD34) (Figure 3B), c-KIT (CD117) (Figure 3C), and DOG1 (Figure 3D). The tumor was eventually confirmed as a gastric GIST. Pathological examination of $\mathrm{H} \& \mathrm{E}$ slides also showed a clearly complete resection margins following m-EFTR (also named as chen-EFTR) (Figure 4).

A prescription of fasting and gastrointestinal decompression was made for three days. Usage of antibiotics 

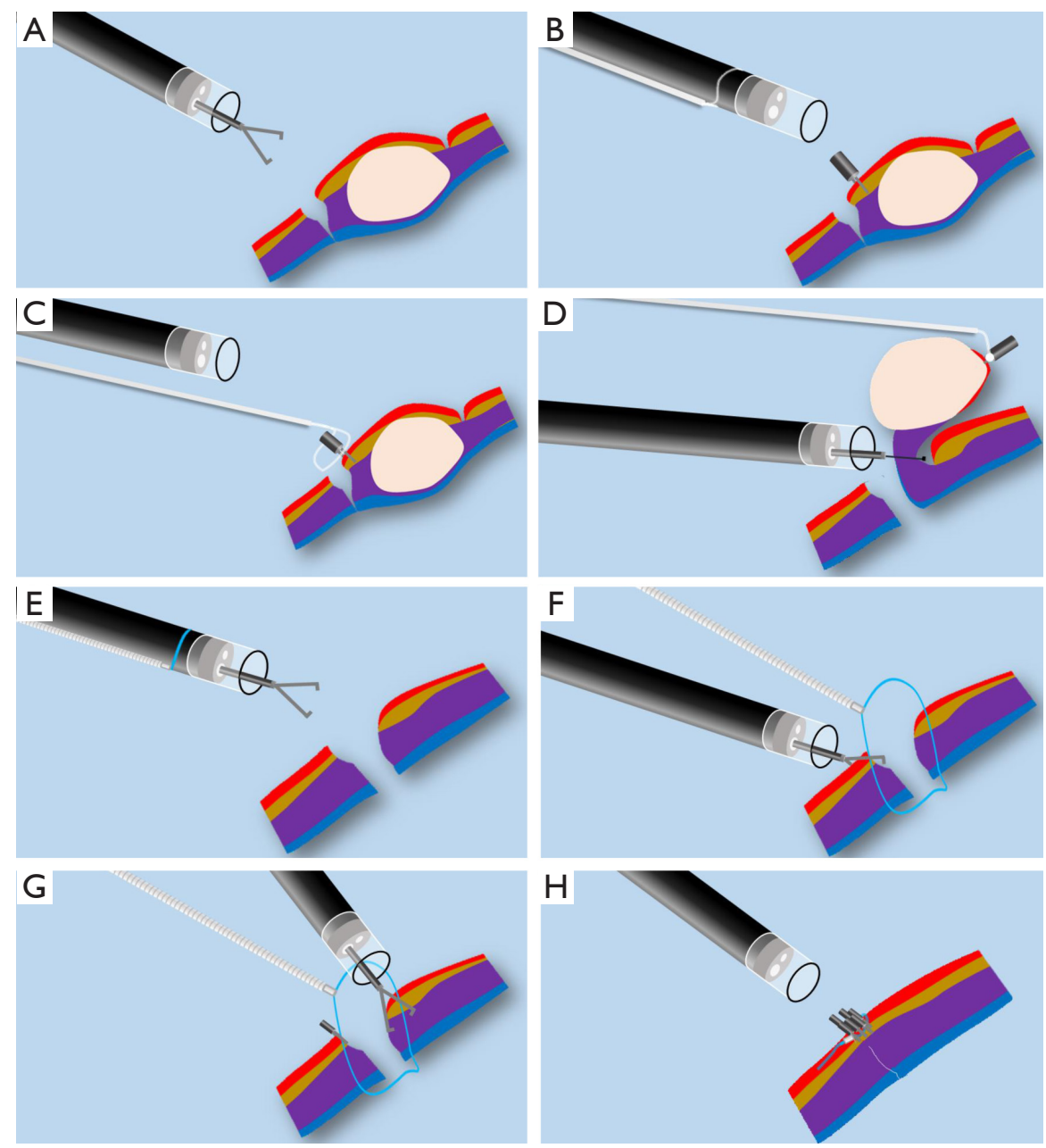

Figure 2 Schematic illustrations of m-EFTR (chen-EFTR). (A) A clip was inserted to stomach through working channel and was placed in marginal mucosa; (B) a snare which was tied in scope was inserted to stomach; (C) the snare was tied on the clip; (D) distinct endoscopic visualization, adequate exposure of cutting line and sufficient operating space was reached through repositioning snare; (E) a clip and a endoloop which was tied on scope was inserted into stomach together; (F) the endoloop was anchored on the normal mucosa with a clip; (G) clips were applied circumferentially; $(\mathrm{H})$ the defect was closed completely after tied completely the endoloop.

and proton pump inhibitor (PPI) was prescribed for three days. Moreover, patient also received fluid replacement and nutritional support during hospitalization. The patient was instructed to try to drink after three days, and was discharged on postoperative day four. Repeated gastroscope examination was suggested to the patient after six months on discharge.

\section{Comments}

GISTs are one of the most common mesenchymal tumors of the alimentary tract. Evidence suggested that all GISTs have malignant potential regardless of size $(4,5)$. Surgery with negative surgical margins is presently regarded as the standard resection for gastric GISTs (6). However, gastric GISTs with small size do not require lymphadenectomy or a generous resection margin due to rare lymph node metastasis and infiltrative growth patterns (7). Therefore, endoscopic complete resection with a microscopically negative margin should be considered preferably (8). Endoscopic removal has several advantages, such as an intact stomach after GISTs removal, avoidance of gastric dysmotility, a relatively short hospital stay, decreased sedation and analgesic requirement, relatively low cost, and 

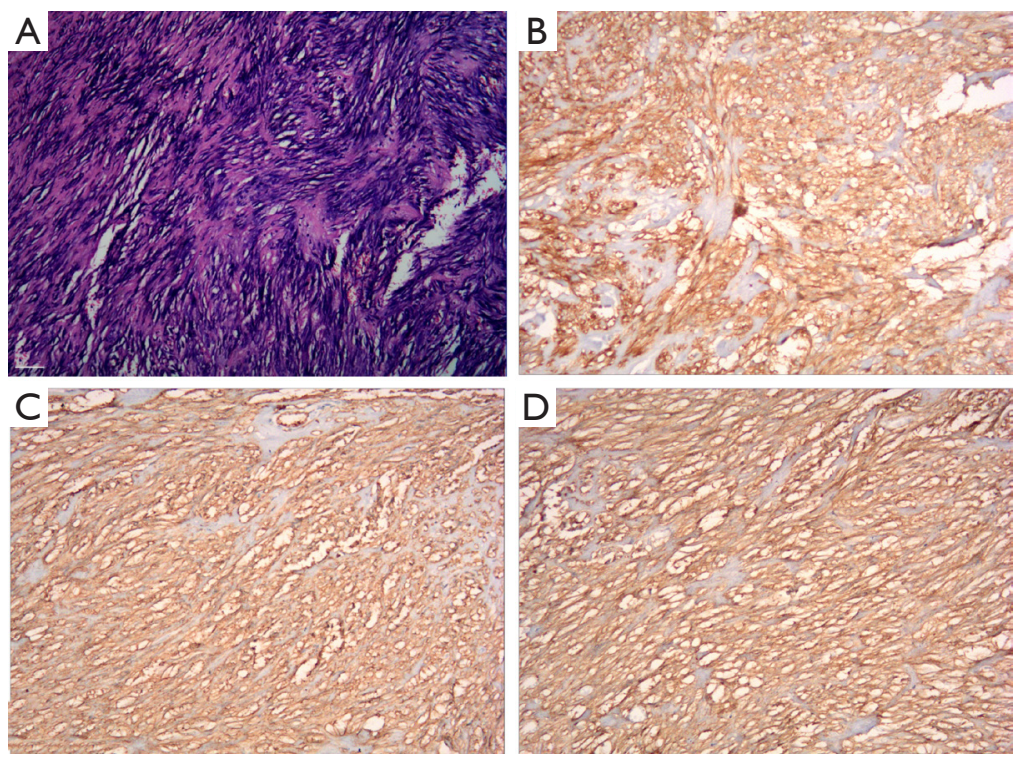

Figure 3 Evidences of confirming the tumor as the GIST. Pathological examination of a H\&E slide shows the spindle cell (A). Hematopoietic progenitor cell antigen (CD34) (B), c-KIT (CD117) (C), and DOG1 (D) were all indicated immunohistochemically to be positive. Magnification, $\times 50$. GIST, gastrointestinal stromal tumor.

fewer human resources required compared with surgery (2).

Some researchers and practitioners recommended submucosal tunneling endoscopic resection (STER) to resect the gastric MP-GISTs because the potential of STER in resecting esophageal SMTs or SMTs in the cardia (9). However, there are also some researchers and practitioners do not think that STER is unsuitable for gastric GISTs because a straight tunnel toward the tumor is sometimes difficultly created. Moreover, it also indicated a difficult to dissect the distal pole of the SMT with STER (1). Certainly, efforts to develop methods of resecting gastric GISTs were never ceased. With the development of various devices and methods to close the wall defect, EFTR is emerging as an alternative method for GISTs (10-12). However, some issues limited the widespread implementation of EFTR in gastric GISTs.

Firstly, poor endoscopic visualization will be encountered when a full-thickness incision was created, which makes difficult to exposure the cutting line. We therefore developed a clip-and-snare traction method to achieve sufficient operational space and inadequately exposure the cutting line inspired by the clip-and-thread traction method (13). It must be noted that more options of traction will be achieved due to great support property of snare. Moreover, the clip-and-snare traction can keep cutting line farther away from abdominal viscera and thus reduce the risk of accidental injury. More importantly, the clip with snare successfully prevented the tumor getting lost into the peritoneal cavity, and facilitated tumor retrieval from the stomach (13).

Secondly, risk of bleeding in the conventional EFTR procedures is high (14) especially if practitioners are encountering limited endoscopic visualization because vessel distribution in greater curvature is rich. It is important to note that vessels can be clearly and safely addressed with electrocoagulation beforehand when clip-and-snare traction method was used to achieve adequate exposure of cutting line. In fact, severe bleeding has not occurred in our case because the tumor was small (13).

Thirdly, complete closure of the defect after performing EFTR is also important. In our case, we used clip with endoloop to close defect because a relatively small defect was created. In fact, several methods have been developed to close defect after EFTR such as clip with endoloop (also termed as purse-string suturing) $(15,16)$ and over-the-scope clip (OTSC) system (17). The purse-string suture is an effective and inexpensive method, and thus is widely used to close defect made by endoscopic surgeries. The OTSC is a relatively novel method to close defect. The potential of OTSC in closing defect has been established, however expensive cost and multiple bites for large defects limit the implementation (13). Beyond that, line-assisted complete closure (LACC) was also developed to close large mucosal 

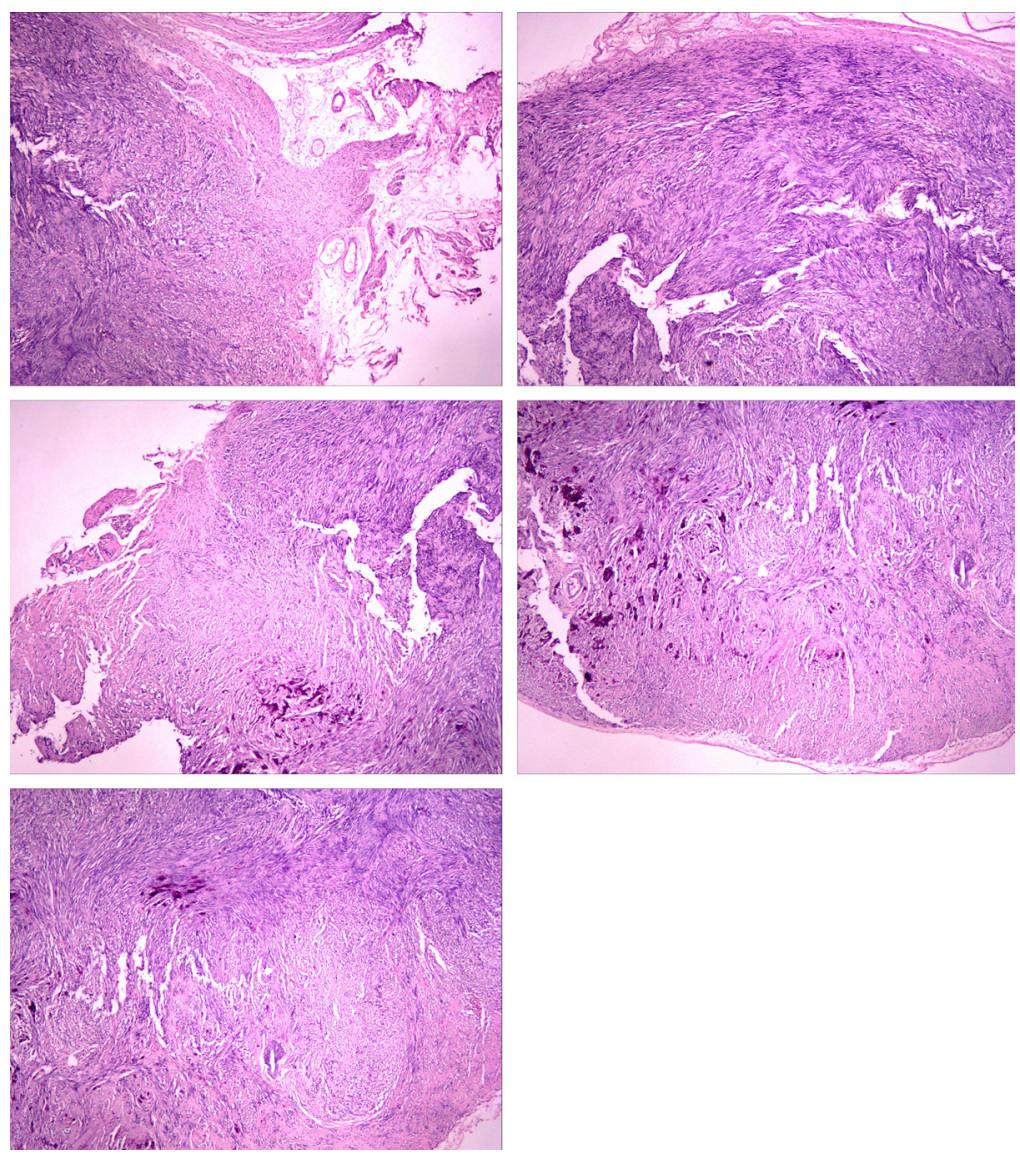

Figure 4 Pathological examination of H\&E slides confirming a clearly complete resection margins following m-EFTR ( $\times 200)$. EFTR, endoscopic full-thickness resection.

defect (18). However, LACC is therefore recommended as an adjunct to repair a remnant hole after purse-string suture or OTSC closure because it is somewhat complicated and insecure for closure of a full-thickness gastric wall defect (1).

As has been said, we believe that this clip- and snareassisted EFTR method (also named as m-EFTR or chenEFTR) provide a new approach for resection of gastric MP-GISTs because it can achieve distinct endoscopic visualization, adequate exposure of cutting line and sufficient operating space.

\section{Acknowledgments}

Funding: None.

\section{Footnote}

Conflicts of Interest: All authors have completed the ICMJE uniform disclosure form (available at http://dx.doi. org/10.21037/jgo.2020.03.12). The authors have no conflicts of interest to declare.

Ethical Statement: The authors are accountable for all aspects of the work in ensuring that questions related to the accuracy or integrity of any part of the work are appropriately investigated and resolved.

Open Access Statement: This is an Open Access article distributed in accordance with the Creative Commons Attribution-NonCommercial-NoDerivs 4.0 International License (CC BY-NC-ND 4.0), which permits the noncommercial replication and distribution of the article with the strict proviso that no changes or edits are made and the original work is properly cited (including links to both the formal publication through the relevant DOI and the license). See: https://creativecommons.org/licenses/by-nc-nd/4.0/. 


\section{References}

1. Shichijo S, Uedo N, Yanagimoto Y, et al. Endoscopic full-thickness resection of gastric gastrointestinal stromal tumor: a Japanese case series. Ann Gastroenterol 2019;32:593-9.

2. ASGE Technology Committee, Aslanian HR, Sethi A, et al. ASGE guideline for endoscopic full-thickness resection and submucosal tunnel endoscopic resection. VideoGIE 2019;4:343-50.

3. Goto O, Takeuchi H, Kitagawa Y, et al. Endoscopic Submucosal Dissection (ESD) and Related Techniques as Precursors of "New Notes" Resection Methods for Gastric Neoplasms. Gastrointest Endosc Clin N Am 2016;26:313-22.

4. Miettinen M, Sarlomo-Rikala M, Lasota J. Gastrointestinal stromal tumors: recent advances in understanding of their biology. Hum Pathol 1999;30:1213-20.

5. Miettinen M, Sobin LH, Lasota J. Gastrointestinal stromal tumors of the stomach: a clinicopathologic, immunohistochemical, and molecular genetic study of 1765 cases with long-term follow-up. Am J Surg Pathol 2005;29:52-68.

6. DeMatteo RP, Lewis JJ, Leung D, et al. Two hundred gastrointestinal stromal tumors: recurrence patterns and prognostic factors for survival. Ann Surg 2000;231:51-8.

7. Fong Y, Coit DG, Woodruff JM, et al. Lymph node metastasis from soft tissue sarcoma in adults. Analysis of data from a prospective database of 1772 sarcoma patients. Ann Surg 1993;217:72-7.

8. Chun SY, Kim KO, Park DS, et al. Endoscopic submucosal dissection as a treatment for gastric subepithelial tumors that originate from the muscularis propria layer: a preliminary analysis of appropriate indications. Surg Endosc 2013;27:3271-9.

9. Xu MD, Cai MY, Zhou PH, et al. Submucosal tunneling endoscopic resection: a new technique for treating upper GI submucosal tumors originating from the muscularis

Cite this article as: Tian X, Shi B, Chen WQ. Modified endoscopic full-thickness resection of gastric stromal tumor originating from the muscularis propria layer. J Gastrointest Oncol 2020;11(2):461-466. doi: 10.21037/jgo.2020.03.12 propria layer (with videos). Gastrointest Endosc 2012;75:195-9.

10. Chen T, Zhou PH, Chu Y, et al. Long-term Outcomes of Submucosal Tunneling Endoscopic Resection for Upper Gastrointestinal Submucosal Tumors. Ann Surg 2017;265:363-9.

11. Huang LY, Cui J, Lin SJ, et al. Endoscopic full-thickness resection for gastric submucosal tumors arising from the muscularis propria layer. World J Gastroenterol 2014;20:13981-6.

12. Zhou PH, Yao LQ, Qin XY, et al. Endoscopic fullthickness resection without laparoscopic assistance for gastric submucosal tumors originated from the muscularis propria. Surg Endosc 2011;25:2926-31.

13. Suzuki S, Gotoda T, Kobayashi Y, et al. Usefulness of a traction method using dental floss and a hemoclip for gastric endoscopic submucosal dissection: a propensity score matching analysis (with videos). Gastrointest Endosc 2016;83:337-46.

14. Yamamoto Y, Uedo N, Abe N, et al. Current status and feasibility of endoscopic full-thickness resection in Japan: Results of a questionnaire survey. Dig Endosc 2018;30 Suppl 1:2-6.

15. Qiao Z, Ling X, Zhu J, et al. Therapeutic application of purse-string sutures with nylon loops and metal clips under single-channel endoscopy for repair of gastrointestinal wall defects. Exp Ther Med 2018;15:4356-60.

16. Shi Q, Chen T, Zhong YS, et al. Complete closure of large gastric defects after endoscopic full-thickness resection, using endoloop and metallic clip interrupted suture. Endoscopy 2013;45:329-34.

17. Kobara H, Mori H, Nishiyama N, et al. Over-thescope clip system: A review of 1517 cases over 9 years. J Gastroenterol Hepatol 2019;34:22-30.

18. Kato M, Takeuchi Y, Yamasaki Y, et al. Technical feasibility of line-assisted complete closure technique for large mucosal defects after colorectal endoscopic submucosal dissection. Endosc Int Open 2017;5:E11-6. 